\title{
First results on migrating shad (Alosa fallax) and mullet (Mugil cephalus) echocounting in a lock on the Rhône River (France) using a split-beam sounder, and relationships with environmental data and fish caught
}

\author{
Jean Guillard ${ }^{\mathrm{a}, \mathrm{b} *}$, Michel Colon ${ }^{\mathrm{a}}$ \\ a Institut national de la recherche agronomique, station d'hydrobiologie lacustre, BP 511, 74203 Thonon-les-Bains cedex, France \\ b Present adress: IRD-HEA, BP 5045, 2051, avenue du Val-de-Montferrand, 34032 Montpellier cedex, France
}

Accepted 18 April 2000

\begin{abstract}
The application of fisheries acoustics in shallow waters opens new fields of observation and allows new methods for abundance estimates. In this paper we deal with echocounting of migrating fish crossing the Beaucaire-Vallabrègues lock, the first obstacle encountered on the Rhône, using a SIMRAD EY500 split-beam sounder, $70 \mathrm{kHz}$ frequency. Two transducers sampled a section of water and evaluated approximately $35 \%$ of the lock section, based on a calibration sphere. The number of fish crossing the lock was calculated for each fish lock. Crossing data for the fish were recorded (dates, position, exit time). The present analysis did not allow the identification of the two major species that cross the dam: shad (Alosa fallax) and mullet (Mugil cephalus). The number of fish counted was positively correlated with the catches per unit effort (CPUE) by recreating fishermen below the dam and with increasing water temperature. () 2000 Ifremer/CNRS/INRA/IRD/Cemagref/Éditions scientifiques et médicales Elsevier SAS
\end{abstract}

hydroacoustic / target strength (TS) / Alosa fallax / Mugil cephalus / Rhône river / migrating fish / lock

\section{INTRODUCTION}

The development of dams and locks on the Rhône River induced important ecological and behavioural changes. Among all of the fish populations present, migrating fish were the most seriously affected. The shad (Alosa fallax rhodanensis) stock, the target species for the Rhône restoration program (Le Corre et al., 1997), decreased drastically, from 50 tons fished in the 1920 's to less than 7 tons at present. The shad did not totally disappear, as 'substitute' spawning grounds appeared downstream of the first dam. Fish ladders were installed so that migrating fish could reach their spawning grounds. However, their poor overall design and the difficulty involved in improving them often made them useless. At the same time, it became evident that the locks provided the fish with a means to cross the dams. In addition to shad, the lock is crossed by a large number of individuals from another species, the mullet (Mugil cephalus).
Since 1993, study surveys have been planned by the MRM association (Migrateur Rhône Méditerranée) at the Beaucaire-Vallabrègues site, the first obstacle encountered by migrating fish. Net fishing, which is difficult to implement and which results are unreliable and fish destructive, cannot be used for counting. The possibility of visually counting the fish by partially lowering the head gate is a very efficient means of counting and determining the different species crossing the lock. But this expensive technique is of limited use, since it requires the presence of more than six people. Moreover, this type of operation creates a great deal of pressure on the gate, which could result in malfunction or even an accident. As a result, only a half dozen of partial lowering operations are allowed during the migration period. The installation of video cameras to count the fish is allowed, but the high turbidity of the river makes this solution impossible.

After the completion of a preliminary survey, a daily assessment of the number of fish crossing the lock was 
made in 1997 and 1998, using a split-beam sounder. Horizontal detection, in either a mobile or fixed location, is especially used to study the spatiotemporal structures of fish in rivers, estuaries, coastal zones, etc. (Lévesque and Harte, 1994; Duncan and Kubecka, 1996; Steig and Johnston, 1996; Gauthier et al., 1997; Burwen and Fleischman, 1998). The purpose of this study was to make daily assessments of migrating fish crossing the lock. A technical note by Guillard and Colon (1998) has already described the techniques and material used. The protocol, which has been automated in 1998 (Colon and Guillard, 1997), was defined to optimise the lock in its capacity as a fish ladder. This note analyses data from the two years surveys and the relationships between the number of fish crossing the dam and environmental data, as well as data related to fish caught below the site.

\section{MATERIAL AND METHODS}

\subsection{Survey site}

The Beaucaire-Vallabrègues dam is located at $58 \mathrm{~km}$ from the sea. Specific maneuvers, attraction currents, filling of the lock and upstream attraction currents, described in the technical note (Guillard and Colon, 1998), are necessary to direct the fish in and outside the lock, and were optimised.

\subsection{Material}

In order to carry out this study, a split-beam SIMRAD EY500 sounder (SIMRAD, 1996) was used. Its main characteristics were a $70 \mathrm{kHz}$ frequency, a $0.2 \mathrm{~ms}$ pulse width, and a 40logR TVG (Time Varied Gain) amplification. The equipment consisted of two circular Simrad ES $70-11$ transducers $\left(11^{\circ}\right.$ of total beam angle at $-3 \mathrm{~dB}$ ), in association with the Simrad sounder and a multiplexer, which allowed the automatic alternative transmission every $2 \mathrm{~s}$. The calibration was performed with a copper sphere $(-39.1 \mathrm{~dB})$ before each annual assessment and repeated regularly (Foote et al., 1987). According to the characteristics of the transducers and the threshold, the volume of water sampled, based on a calibration sphere, was equal to $35 \%$ of the total volume of the lock section, with no overlap area between the two transducers.

\subsection{Shad}

The shad is an anadromous fish, which migrates in spring, as a function of the physical environment characteristics. Not as good a swimmer as the salmon, it avoids strong, highly oxygenated currents in which it becomes disoriented (Larinier and Travade, 1992). It is a Clupeidae with a total length between 0.25 and $0.45 \mathrm{~m}$ (Le Corre et al., 1997). The equation given by MacLennan and Simmonds (1992) in relation to Clupeidae $[T S=20 \log (L)-71.9$ with $L$ in $\mathrm{cm}$ and $T S$ in $\mathrm{dB}$, calculated in vertical emission, gives $T S$ values of
-43.94 and $-38.8 \mathrm{~dB}$, respectively, for the above lengths. The $T S$ values are lower and more variable when a horizontal type of emission is used (Kubecka and Duncan, 1998). The selected threshold of $-55 \mathrm{~dB}$ makes it possible to discard targets of a smaller size and prevents the saturation of the system as well as the loss of migratory fish. The criteria chosen to differentiate individual targets are those recommended by SIMRAD.

\subsection{Data acquisition}

With a split-beam sounder, given the split-beam angles and the directivity function of the transducer, it is possible to calculate the target strength (TS) of the targets and to measure the speed and direction of fish (MacLennan and Simmonds, 1992). As a result, we can differentiate between targets moving upstream and downstream, and thus focus on migrating fish. In the case of observations made from a fixed location and with horizontal deployment, as used in this study, echocounting techniques had to be used in most of the cases (Thorne, 1998). Data were processed by the SIMRAD EP500 analysis program (Version 5.2, SIM$\mathrm{RAD}, 1996)$ and gave the target characteristics for each fish lock.

The number of fish crossing the dam was counted for each fish lock and varies greatly. Data had to be analysed over longer periods of time to be able to account for daily fluctuations. Since weekly trends did not make it possible to analyse fluctuations over short periods of time, it was decided to analyse the trend in the number of migrating fish over a period of 4 days. The system used was remote control operated. The lock keeper called by phone the laboratory and then we made the connection by modem to activate the sounder. Problems involving the regularity of phone calls prompted us to automate the system (Colon and Guillard, 1997).

\subsection{Environmental and fishing data}

Environmental data (water temperature, flow of the Rhône, $\mathrm{pH}$, conductivity and turbidity) were gathered by MRM. Recreating fishing consisted of using a $4 \mathrm{~m}$ size square dipping-net, with a mesh between 27 and $40 \mathrm{~mm}$, attached to a pole from a raft or a boat located next to the bank. In addition to the catches (weight, total length, sex, number of individuals caught), the fishing effort involved (actual fishing time, number of set per hour) was also taken into account. These catches per unit effort (CPUE) were assumed to be proportional to the stock below the dam. Fluctuations over short periods of time were also very important for CPUE data and it was necessary to examine trends over time periods of 4 days. 

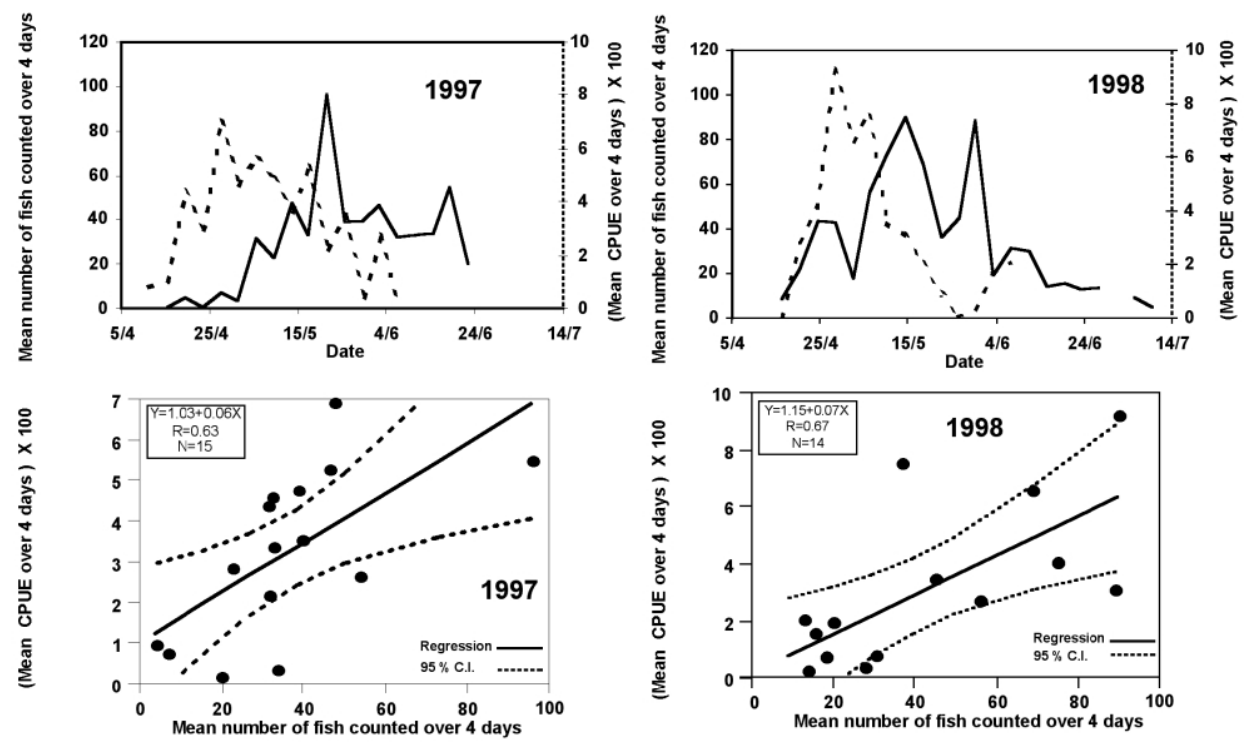

Figure 1. Trends in the number of fish crossing the lock and catches per unit effort (CPUE) below the dam; the dates on the graphs correspond to the first day of the week. Relationship of the number of fish counted during 4 days and the CPUEs over 4 days, 16 days before (1997 and 1998 surveys).

\section{RESULTS}

\subsection{Number of fish counted and CPUEs}

The total number of fish which crossed the lock and the CPUEs below the dam for the 1997 and 1998 surveys varied in relation to time. A shift in the trend for both categories of data was observed (figure 1). The maximum correlation between the mean CPUEs over a period of 4 days and the mean number of fish counted over a period of 4 days was calculated for an interval of 16 days, at a risk level of 5\% (figure 1).

\subsection{Acoustic counting and environmental data}

The mean number of fish counted by 'fish lock' was positively correlated (significance level of 5\%) with the mean daily temperature for the surveys of 1997 and 1998 (figure 2), until the peak was reached. Between the mean number of fish counted and the average flow of the Rhône, there was a non-significant positive relationship $(r=0.59, n=10$, significance level of 5\%), for data from the 1997 survey, and a significant negative relationship ( $r=0.84, n=8$, significance level of 5\%) for data from the 1998 survey. No significant relationship could be found between the number of fish counted and either conductivity, $\mathrm{pH}$ or oxygen content of the Rhône. Trends in relation to the different lunar phases did not contribute any additional information.

\section{DISCUSSION - CONCLUSION}

When a lock is used as a fish ladder, it is an effective system, which helps the fish to cross the dam. It could be used for other locks on the Rhône in order to help the fish cross other dams located further upstream. Automated systems permit to increase the number of locks studied and improve the results. The measurements
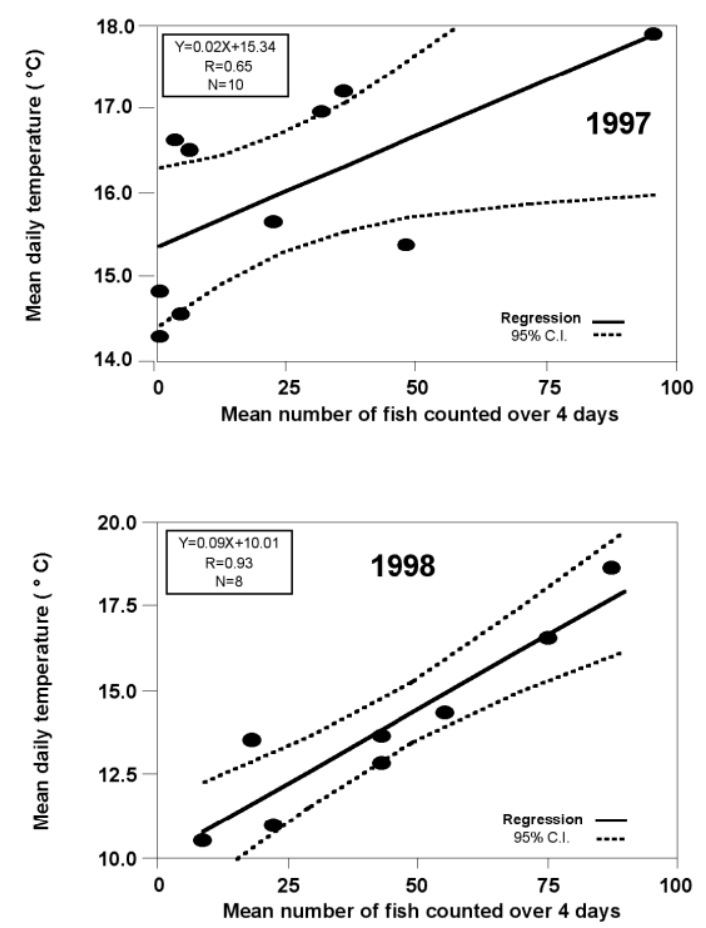

Figure 2. Correlation between the mean number of fish counted (4 days) and the mean daily temperature over 4 days (1997 and 1998 surveys). 
indicated that for the selected settings, the two transducers sampled $35 \%$ of the lock section. The sampling was not exhaustive and the number of fish counted was only part of the total number of migrating fish. In any case, it was impossible to count all of the fish that pass through, since some of them crossed the dam when boats passed through. This counting method makes it possible to measure trends in the number of fish that cross the dam, and therefore, to monitor the differences in stock from one year to the next.

Data from recreating fishing, representative of the shad stock, were positively correlated to the number of fish counted. The presence of fish below the dam was significant of the beginning of migration, as the fish have already begun to go up the river. An interval of 16 days observed between the CPUEs for amateur fishing below the lock and the number of fish counted represents the delay before the beginning of dam crossing behaviour. This behaviour was related to the maturation of the fish and, therefore, to the temperature. A positive correlation between the mean daily temperature and the number of fish counted could be observed until migration reaches its peak. On the other hand, it was not possible to establish a relationship between the number of fish counted and other environmental parameters $(\mathrm{pH}$, turbidity, oxygen, lunar phases, etc.), because their roles are less important in triggering migration. Correlations between the number of fish counted and the river flow which were positive one year and negative the year after clearly illustrate the complexity of a highly developed river system.

While the distinction between groups of fish of greatly varying sizes is possible by comparing the TS or the pulse widths (Brandt, 1996; Burwen and Fleischman, 1998), it was not possible in our study because the morphometric characteristics of shad and mullet are too similar, the intrinsic variability of the TS is great for horizontal transmissions (Kubecka and Duncan, 1998), and complicated by the fact that the fish are moving and not always seen from the same angle (Gauthier et al., 1997). Moreover, the turbid environment of the Rhône results in some loss in sound energy, which can lead to great variations in the TS measurement (Trevorrow, 1998).

The study of other parameters, such as crossing speed as well as the position of targets in the lock, did not make it possible to identify the two species. It would be necessary to operate the fish locks when shad are not migrating in order to obtain additional data, which would make it possible to identify behaviours characteristics of mullet, and distinguish them from shad. According to available information about the different parameters (speed, TS, distribution, etc.), differentiation between the two species seems difficult. But since mullet go up the Rhône in a random manner, and since data were based on an average, their passage could be considered to be as a background noise. As a result, we can assume that the number of fish counted was proportional to the shad stock in the Rhône, making it possible for us to make annual assessments.
Acknowledgements. We thank J-Y. Menella and MRM for providing financial support.

\section{References}

Brandt, S.B., 1996. Acoustic assessment of fish abundance and distribution. In: Murphy, B.R., Willis, D.W. (Eds.), Fisheries techniques. American Fisheries Society, Bethesda, Maryland, USA, pp. 385-432.

Burwen, D.L., Fleischman, S.J., 1998. Evaluation of sideaspect target strength and pulse width as potential hydroacoustic discriminators of fish species in rivers. Can. J. Fish. Aquat. Sci. 55, 2492-2502.

Colon, B., Guillard, J., 1997. Programme d'automatisation de l'acquisition des données acoustiques lors des éclusées à poissons. Rapport Institut de limnologie, Thonon, 124.

Duncan, A., Kubecka, J., 1996. Patchiness of longitudinal fish distributions in a river as revealed by a continuous hydroacoustic survey. ICES J. Mar. Sci. 53, 161-166.

Foote, K.H., Knudsen, H.P., Vestnes, G., MacLennan, D.N., Simmonds E.J., 1987. Calibration of acoustic instruments for fish density estimation: a practical guide. ICES Coop. Res. Rep.

Gauthier, S., Boisclair, D., Legendre, X., 1997. Evaluation of a variable angle scanning method to estimate relative abundance and distribution of fish using a single-beam echosounder in shallow lakes. J. Fish Biol. 50, 208-221.

Guillard, J., Colon, B., 1998. Estimation hydroacoustique du nombre de poissons migrateurs franchissant l'écluse de Beaucaire-Vallabrégues (Rhône). Bull. Fr. Pêche Piscic. 348, 79-90.

Kubecka, J., Duncan, A., 1998. Acoustic size vs. real size relationships for common species of riverine fish. Fish. Res. 35, 115-125.

Larinier, M., Travade, F., 1992. La conception des dispositifs de franchissement pour les aloses. Bull. Fr. Pêche Piscic. 327, 125-133.

Le Corre, M., Bagliniere, J.L., Sabatier, R., Menella, J.Y., Pont, D., 1997. Données récentes sur les caractéristiques morphologiques et biologiques de la population d'Alose feinte du Rhône (Alosa fallax rhodanensis Roule, 1924) Bull.. Fr. Pêche Piscic. 346, 527-545.

Lévesque, F., Harte, M.K., 1994. Application de l'hydroacoustique en milieu fluvial : exemple de l'étude de la montaison du saumon atlantique (Salmo salar L.) par sondage à double faisceau dans la rivière Moisie, Québec. Bull. Fr. Pêche Piscic. 332, 33-41.

MacLennan, D.N., Simmonds, E.J., 1992. Fisheries acoustics, Fish and fisheries serie. Chapman and Hall, London.

SIMRAD, 1996. Instruction manual, portable scientific echo sounder, P2473E, $36 \mathrm{p}$ and EP500: Instruction manual, echo processing system, P259E.

Steig, T.W., Johnston, S.V., 1996. Monitoring fish movement patterns in a reservoir using horizontally scanning splitbeam techniques. ICES J. Mar. Sci. 53, 435-441.

Thorne, R.E., 1998. Experiences with shallow water acoustics. Fish. Res. 35, 137-141.

Trevorrow, M.V., 1998. Boundary scattering limitations to fish detection in shallow waters. Fish. Res. 35, 127-135. 